\title{
On $\left(\Delta^{m}, I\right)$-Statistical Convergence of Order $\alpha$
}

\author{
Mikail Et, ${ }^{1}$ Abdullah Alotaibi, ${ }^{2}$ and S. A. Mohiuddine ${ }^{2}$ \\ ${ }^{1}$ Department of Mathematics, Firat University, 23119 Elazıg, Turkey \\ ${ }^{2}$ Department of Mathematics, Faculty of Science, King Abdulaziz University, P.O. Box 80203, Jeddah 21589, Saudi Arabia
}

Correspondence should be addressed to S. A. Mohiuddine; mohiuddine@gmail.com

Received 31 August 2013; Accepted 6 November 2013; Published 9 February 2014

Academic Editors: H. Bulut, Y. Deng, and K.-L. Hsiao

Copyright (c) 2014 Mikail Et et al. This is an open access article distributed under the Creative Commons Attribution License, which permits unrestricted use, distribution, and reproduction in any medium, provided the original work is properly cited.

The idea of $I$-convergence of real sequences was introduced by Kostyrko et al., (2000/01) and also independently by Nuray and Ruckle (2000). In this paper, we introduce the concepts of $\left(\Delta^{m}, I\right)$-statistical convergence of order $\alpha$ and strong $\left(\Delta_{p}^{m}, I\right)$-Cesàro summability of order $\alpha$ of real sequences and investigated their relationship.

\section{Introduction}

The idea of statistical convergence was given by Zygmund [1] in the first edition of his monograph published in Warsaw in 1935. The concept of statistical convergence was introduced by Steinhaus [2] and Fast [3] and later reintroduced by Schoenberg [4] independently. Later on it was further investigated from the sequence space point of view and linked with summability theory by Connor [5], Cinar et al. [6], Et et al. [7], Fridy [8], Güngör et al. [9, 10], Işik [11], Mohiuddine et al. [12-14], Mursaleen [15], Šalát [16], and many others.

The idea of $I$-convergence of real sequences was introduced by Kostyrko et al. [17] and also independently by Nuray and Ruckle [18] (who called it generalized statistical convergence) as a generalization of statistical convergence. Later $I$ convergence was studied by Das et al. [19-21], Kostyrko et al. [22], Mohiuddine et al. [23-25], Šalát et al. [26, 27], Tripathy and Hazarika $[28,29]$, and many others.

In this paper, we introduce the concepts of $\left(\Delta^{m}, I\right)$ statistical convergence of order $\alpha$ and strong $\left(\Delta_{p}^{m}, I\right)$-Cesàro summability of order $\alpha$ of real sequences and investigated their relationship. In Section 2 we give a brief overview about statistical convergence, strong $p$-Cesàro summability, $I$-convergence, and difference sequences. In Theorem 8 , we give the inclusion relations between the sets of $S^{\alpha}\left(\Delta^{m}, I\right)$ convergent sequences and $w^{\alpha}\left(\Delta_{p}^{m}, I\right)$-summable sequences. In Theorem 10, we give the relationship between $w^{\alpha}\left(\Delta_{p}^{m}, I\right)$ summable sequences for different $\alpha$ 's. In Theorem 12 , we give the relationship between the sets of $S^{\alpha}\left(\Delta^{m}, I\right)$-convergent sequences for different $\alpha$ 's.

\section{Definition and Preliminaries}

Let $w$ be the set of all sequences of real or complex numbers and let $\ell_{\infty}, c$, and $c_{0}$ be, respectively, the Banach spaces of bounded, convergent, and null sequences $x=\left(x_{k}\right)$ with the usual norm $\|x\|=\sup \left|x_{k}\right|$, where $k \in \mathbb{N}=\{1,2, \ldots\}$, the set of positive integers. Also by $b s, c s, \ell_{1}$, and $\ell_{p}$, we denote the spaces of all bounded, convergent, and absolutely and $p$ absolutely convergent series, respectively.

The definitions of statistical convergence and strong $p$ Cesàro convergence of a sequence of real numbers were introduced in the literature independently of one another and followed different lines of development since their first appearance. It turns out, however, that the two definitions can be simply related to one another in general and are equivalent for bounded sequences. The idea of statistical convergence depends on the density of subsets of the set $\mathbb{N}$. The density of a subset $E$ of $\mathbb{N}$ is defined by

$$
\delta(E)=\lim _{n \rightarrow \infty} \frac{1}{n} \sum_{k=1}^{n} \chi_{E}(k) \text { provided the limit exists, }
$$

where $\chi_{E}$ is the characteristic function of $E$. It is clear that any finite subset of $\mathbb{N}$ has zero natural density and $\delta\left(E^{c}\right)=$ $1-\delta(E)$. 
The order of statistical convergence of a sequence of numbers was given by Gadjiev and Orhan in [30] and then statistical convergence of order $\alpha$ and strong $p$-Cesàro summability of order $\alpha$ were studied by Çolak [31].

The notion of difference sequence spaces was introduced by Kizmaz [32] and it was generalized by Et et al. [33-35] such as

$$
\Delta^{m}(X)=\left\{x=\left(x_{k}\right):\left(\Delta^{m} x_{k}\right) \in X\right\},
$$

for $X=\ell_{\infty}, c$, or $c_{0}$, where $m \in \mathbb{N}, \Delta^{0} x=\left(x_{k}\right), \Delta^{m} x=$ $\left(\Delta^{m-1} x_{k}-\Delta^{m-1} x_{k+1}\right)$, and so $\Delta^{m} x_{k}=\sum_{i=0}^{m}(-1)^{i}\left(\begin{array}{c}m \\ i\end{array}\right) x_{k+i}$. The sequence spaces $\Delta^{m}(X)$ are Banach spaces normed by

$$
\|x\|_{\Delta}=\sum_{i=1}^{m}\left|x_{i}\right|+\left\|\Delta^{m} x_{k}\right\|_{\infty}
$$

for $X=\ell_{\infty}, c$, or $c_{0}$. Let $X$ be any sequence spaces, if $x \in$ $\Delta^{m}(X)$, then there exists one and only one $y=\left(y_{k}\right) \in X$ such that

$$
\begin{aligned}
x_{k}= & \sum_{i=1}^{k-m}(-1)^{m}\left(\begin{array}{c}
k-i-1 \\
m-1
\end{array}\right) y_{i} \\
= & \sum_{i=1}^{k}(-1)^{m}\left(\begin{array}{c}
k+m-i-1 \\
m-1
\end{array}\right) y_{i-m}, \\
y_{1-m} & =y_{2-m}=\cdots=y_{0}=0,
\end{aligned}
$$

for sufficiently large $k$; for instance, $k>2 m$. We use this fact in the following examples.

Recently, the difference sequence spaces have been studied in $[10,34,36-39]$.

Let $X$ be nonempty set. Then a family of sets $I \subset 2^{X}$ (power sets of $X$ ) is said to be an ideal if $I$ is additive, that is, $A, B \in I$ implies $A \cup B \in I$, and hereditary; that is, $A \in I$, $B \subset A$ implies $B \in I$.

A nonempty family of sets $F \subset 2^{X}$ is said to be a filter of $X$ if and only if (i) $\phi \notin F$, (ii) $A, B \in F$ implies $A \cap B \in F$, and (iii) $A \in F, A \subset B$ implies $B \in F$.

An ideal $I \subset 2^{X}$ is called nontrivial if $I \neq 2^{X}$.

A nontrivial ideal $I$ is said to be admissible if $I \supset\{\{x\}$ : $x \in X\}$.

If $I$ is a nontrivial ideal in $X(X \neq \phi)$, then the family of sets $F(I)=\{M \subset X:(\exists A \in I)(M=X \backslash A)\}$ is a filter of $X$, called the filter associated with $I$.

Throughout the paper I will stand for a nontrivial admissible ideal of $\mathbb{N}$.

We now introduce our main definitions.

Definition 1 (see [40]). A sequence $x \in w$ is said to be $I$ convergent if there exists $L \in \mathbb{C}$ such that, for all $\varepsilon>0$, the set $\left\{n \in \mathbb{N}:\left|\Delta^{m} x_{k}-L\right| \geq \varepsilon\right\} \in I$. In this case, one writes $\left(\Delta^{m}, I\right)-\lim x_{k}=L$. The set of all $\left(\Delta^{m}, I\right)$-convergent sequences will be denoted by $c\left(\Delta^{m}, I\right)$.

Definition 2. Let $\alpha \in(0,1]$ be any real number. The sequence $x \in w$ is said to be $\left(\Delta^{m}, I\right)$-statistical convergence of order $\alpha$ (or $S^{\alpha}\left(\Delta^{m}, I\right)$-convergence) if there is a real number $L$ such that

$$
\left\{n \in \mathbb{N}: \frac{1}{n^{\alpha}}\left|\left\{k \leq n:\left|\Delta^{m} x_{k}-L\right| \geq \varepsilon\right\}\right| \geq \delta\right\} \in I .
$$

In this case, we write $S^{\alpha}\left(\Delta^{m}, I\right)-\lim x_{k}=L$ or $S^{\alpha}(I)-$ $\lim \Delta^{m} x_{k}=L$. The set of all $\left(\Delta^{m}, I\right)$-statistically convergent sequences of order $\alpha$ will be denoted by $S^{\alpha}\left(\Delta^{m}, I\right)$. In the special case $\alpha=1$, we will write $S\left(\Delta^{m}, I\right)$ instead of $S^{\alpha}\left(\Delta^{m}, I\right)$.

$\left(\Delta^{m}, I\right)$-statistical convergence of order $\alpha$ is well defined for $0<\alpha \leq 1$, but it is not well defined for $\alpha>1$ in general. For this $x=\left(x_{k}\right)$ is defined as follows:

$$
\Delta^{m} x_{k}=\left\{\begin{array}{ll}
1, & \text { if } k=2 n ; \\
0, & \text { if } k \neq 2 n ;
\end{array} \quad n=1,2,3, \ldots\right.
$$

For every $\varepsilon>0$ and $\alpha>1$ we have

$$
\frac{1}{n^{\alpha}}\left|\left\{k \leq n:\left|\Delta^{m} x_{k}-1\right| \geq \varepsilon\right\}\right| \leq \frac{n}{2 n^{\alpha}},
$$

and so for any $\delta>0$

$$
\begin{gathered}
\left\{n \in \mathbb{N}: \frac{1}{n^{\alpha}}\left|\left\{k \leq n:\left|\Delta^{m} x_{k}-1\right| \geq \varepsilon\right\}\right| \geq \delta\right\} \\
\subset\left\{n \in \mathbb{N}: \frac{n}{2 n^{\alpha}} \geq \delta\right\} \in I, \\
\frac{1}{n^{\alpha}}\left|\left\{k \leq n:\left|\Delta^{m} x_{k}-0\right| \geq \varepsilon\right\}\right| \leq \frac{n}{2 n^{\alpha}},
\end{gathered}
$$

we have

$$
\begin{aligned}
& \left\{n \in \mathbb{N}: \frac{1}{n^{\alpha}}\left|\left\{k \in I_{n}:\left|\Delta^{m} x_{k}-0\right| \geq \varepsilon\right\}\right| \geq \delta\right\} \\
& \quad \subset\left\{n \in \mathbb{N}: \frac{n}{2 n^{\alpha}} \geq \delta\right\} \in I .
\end{aligned}
$$

Therefore, the sequence $x=\left(x_{k}\right)$ is $\left(\Delta^{m}, I\right)$-statistically convergent of order $\alpha$, both to 1 and 0 ; that is, $S^{\alpha}\left(\Delta^{m}, I\right)-$ $\lim x_{k}=1$ and $S^{\alpha}\left(\Delta^{m}, I\right)-\lim x_{k}=0$. But this is impossible.

It is easy to see that every $\left(\Delta^{m}, I\right)$-convergent sequence is $\left(\Delta^{m}, I\right)$-statistically convergent of order $\alpha(0<\alpha \leq 1)$, but converse does not hold. For this, consider a sequence $x=\left(x_{k}\right)$ defined by

$$
\Delta^{m} x_{k}=\left\{\begin{array}{ll}
\frac{1}{\sqrt{k}}, & k \neq m^{3} \\
1, & k=m^{3}
\end{array} \quad m=1,2, \ldots\right.
$$

It is clear that $x \in S^{\alpha}\left(\Delta^{m}, I\right)$ for $\alpha \in(1 / 3,1]$, but $x \notin c\left(\Delta^{m}, I\right)$.

Definition 3. Let $\alpha \in(0,1]$ be any real number and let $p$ be a positive real number. A sequence $x \in w$ is said to be strong $\left(\Delta_{p}^{m}, I\right)$-Cesàro summable of order $\alpha$ (or strong $w^{\alpha}\left(\Delta_{p}^{m}, I\right)$ summable) if there is a real number $L$ such that

$$
\left\{n \in \mathbb{N}: \frac{1}{n^{\alpha}} \sum_{k=1}^{n}\left|\Delta^{m} x_{k}-L\right|^{p} \geq \varepsilon\right\} \in I .
$$


In this case, we write $w^{\alpha}\left(\Delta_{p}^{m}, I\right)-\lim x_{k}=L$. The set of all strong $\left(\Delta_{p}^{m}, I\right)$-Cesàro summable sequences of order $\alpha$ to $L$ will be denoted by $w^{\alpha}\left(\Delta_{p}^{m}, I\right)$. In the special case $\alpha=1$, we will write $w\left(\Delta_{p}^{m}, I\right)$ instead of $w^{\alpha}\left(\Delta_{p}^{m}, I\right)$.

\section{Main Results}

In this section, we give the main results of this paper. In Theorem 8 we give the inclusion relations between the sets of $S^{\alpha}\left(\Delta^{m}, I\right)$-convergent sequences and $w^{\alpha}\left(\Delta_{p}^{m}, I\right)$ summable sequences. In Theorem 10, we give the relationship between $w^{\alpha}\left(\Delta_{p}^{m}, I\right)$-summable sequences for different $\alpha$ 's. In Theorem 12, we give the relationship between the sets of $S^{\alpha}\left(\Delta^{m}, I\right)$ - convergent sequences for different $\alpha$ s.

Theorem 4. Let $\alpha \in(0,1]$ be any real number and suppose that $S^{\alpha}\left(\Delta^{m}, I\right)-\lim x_{k}=L_{1}, S^{\alpha}\left(\Delta^{m}, I\right) \lim y_{k}=L_{2}$, and $c \in \mathbb{R}$; then

(i) $S^{\alpha}\left(\Delta^{m}, I\right)-\lim c x_{k}=c L_{1}$,

(ii) $S^{\alpha}\left(\Delta^{m}, I\right)-\lim \left(x_{k}+y_{k}\right)=L_{1}+L_{2}$.

Proof. (i) Suppose that $S^{\alpha}\left(\Delta^{m}, I\right)-\lim x_{k}=L_{1}$ and $c \in \mathbb{R}$; then

$$
\begin{aligned}
& \frac{1}{n^{\alpha}}\left|\left\{k \leq n:\left|\Delta^{m}\left(c x_{k}\right)-c L_{1}\right| \geq \varepsilon\right\}\right| \\
& \quad \leq \frac{1}{n^{\alpha}}\left|\left\{k \leq n:\left|\Delta^{m} x_{k}-L_{1}\right| \geq \frac{\varepsilon}{|c|}\right\}\right|<\frac{\delta}{2},
\end{aligned}
$$

and so $S^{\alpha}\left(\Delta^{m}, I\right)-\lim \left(c x_{k}\right)=c L_{1}$.

(ii) Now suppose that $S^{\alpha}\left(\Delta^{m}, I\right)-\lim x_{k}=L_{1}$ and $S^{\alpha}\left(\Delta^{m}, I\right)-\lim y_{k}=L_{2}$; then we have

$$
\begin{aligned}
A_{1} & =\left\{n \in \mathbb{N}: \frac{1}{n^{\alpha}}\left|\left\{k \leq n:\left|\Delta^{m} x_{k}-L_{1}\right| \geq \frac{\varepsilon}{2}\right\}\right|<\frac{\delta}{2}\right\} \\
& \in F(I), \\
A_{2} & =\left\{n \in \mathbb{N}: \frac{1}{n^{\alpha}}\left|\left\{k \leq n:\left|\Delta^{m} y_{k}-L_{2}\right| \geq \frac{\varepsilon}{2}\right\}\right|<\frac{\delta}{2}\right\} \\
& \in F(I),
\end{aligned}
$$

and so $A_{1} \cap A_{2} \neq \phi$. Now for all $n \in A_{1} \cap A_{2}$, we have

$$
\begin{aligned}
\frac{1}{n^{\alpha}} \mid\{k & \left.\leq n:\left|\Delta^{m}\left(x_{k}+y_{k}\right)-\left(L_{1}+L_{2}\right)\right| \geq \varepsilon\right\} \mid \\
\leq & \frac{1}{n^{\alpha}}\left|\left\{k \leq n:\left|\Delta^{m} x_{k}-L_{1}\right| \geq \frac{\varepsilon}{2}\right\}\right| \\
& +\frac{1}{n^{\alpha}}\left|\left\{k \leq n:\left|\Delta^{m} y_{k}-L_{2}\right| \geq \frac{\varepsilon}{2}\right\}\right|<\delta .
\end{aligned}
$$

Then

$$
\begin{aligned}
A_{3}= & \left\{n \in \mathbb{N}: \frac{1}{n^{\alpha}}\left|\left\{k \leq n:\left|\Delta^{m}\left(x_{k}+y_{k}\right)-\left(L_{1}+L_{2}\right)\right| \geq \varepsilon\right\}\right|\right. \\
& <\delta\} \in F(I) .
\end{aligned}
$$

Hence $S^{\alpha}\left(\Delta^{m}, I\right)-\lim \left(x_{k}+y_{k}\right)=L_{1}+L_{2}$.
The proofs of the following two theorems are easy and thus omitted.

Theorem 5. Let $\alpha \in(0,1]$ be any real number; then the limit of any $S^{\alpha}\left(\Delta^{m}, I\right)$-convergent sequence is uniquely determined.

Theorem 6. Let $x=\left(x_{k}\right), y=\left(y_{k}\right)$, and $z=\left(z_{k}\right)$ be real sequences such that $\Delta^{m} x_{k} \leq \Delta^{m} y_{k} \leq \Delta^{m} z_{k}$. If $S^{\alpha}\left(\Delta^{m}, I\right)-$ $\lim x_{k}=L=S^{\alpha}\left(\Delta^{m}, I\right)-\lim z_{k}$, then $S^{\alpha}\left(\Delta^{m}, I\right)-\lim y_{k}=L$.

The proof of the following theorem is obtained by using the same techniques of Savas and Das [21, Theorem 2.4]; therefore we give it without proof.

Theorem 7. Let $\alpha \in(0,1]$ be any real number, then $S^{\alpha}\left(\Delta^{m}, I\right) \cap \ell_{\infty}\left(\Delta^{m}\right)$ is a closed subset of $\ell_{\infty}\left(\Delta^{m}\right)$.

In the following theorem we investigate the relationship between $S^{\alpha}\left(\Delta^{m}, I\right)$-statistically convergent sequences and strong $w^{\alpha}\left(\Delta_{p}^{m}, I\right)$-summable sequences.

Theorem 8. Let $\alpha$ and $\beta$ be fixed real numbers such that $0<\alpha \leq \beta \leq 1$, and let $p$ be a positive real number; then $w^{\alpha}\left(\Delta_{p}^{m}, I\right) \subset S^{\beta}\left(\Delta^{m}, I\right)$, and the inclusion is strict.

Proof. Let $\varepsilon>0$ and $w^{\alpha}\left(\Delta_{p}^{m}, I\right)-\lim x_{k}=L$; then we can write

$$
\begin{aligned}
\sum_{k=1}^{n}\left|\Delta^{m} x_{k}-L\right|^{p} & \geq \sum_{k=1,\left|\Delta^{m} x_{k}-L\right| \geq \varepsilon}^{n}\left|\Delta^{m} x_{k}-L\right|^{p} \\
& \geq \varepsilon^{p}\left|\left\{k \leq n:\left|\Delta^{m} x_{k}-L\right| \geq \varepsilon\right\}\right|,
\end{aligned}
$$

and so

$$
\frac{1}{\varepsilon^{p} n^{\alpha}} \sum_{k=1}^{n}\left|\Delta^{m} x_{k}-L\right|^{p} \geq \frac{1}{n^{\beta}}\left|\left\{k \leq n:\left|\Delta^{m} x_{k}-L\right| \geq \varepsilon\right\}\right| .
$$

Then for any $\delta>0$, we have

$$
\begin{aligned}
& \left\{n \in \mathbb{N}: \frac{1}{n^{\alpha}}\left|\left\{k \leq n:\left|\Delta^{m} x_{k}-L\right| \geq \varepsilon\right\}\right| \geq \delta\right\} \\
& \subseteq\left\{n \in \mathbb{N}: \frac{1}{n^{\beta}} \sum_{k=1}^{n}\left|\Delta^{m} x_{k}-L\right|^{p} \geq \varepsilon^{p} \delta\right\} \in I .
\end{aligned}
$$

This completes the proof.

Taking $\alpha=\beta$, we show the strictness of the inclusion $w^{\alpha}\left(\Delta_{p}^{m}, I\right) \subset S^{\beta}\left(\Delta^{m}, I\right)$ for a special case. For this, consider the sequence $x=\left(x_{k}\right)$ defined by

$$
\Delta^{m} x_{k}=\left\{\begin{array}{ll}
1, & \text { if } k=m^{2}, \\
0, & \text { if } k \neq m^{2},
\end{array} \quad m=1,2, \ldots\right.
$$

For every $\varepsilon>0$ and $\alpha \in(1 / 2,1]$ we have

$$
\frac{1}{n^{\alpha}}\left|\left\{k \leq n:\left|\Delta^{m} x_{k}-0\right| \geq \varepsilon\right\}\right| \leq \frac{\sqrt{n}}{n^{\alpha}}=\frac{1}{n^{\alpha-1 / 2}},
$$


and for any $\delta>0$ we get

$$
\begin{aligned}
& \left\{n \in \mathbb{N}: \frac{1}{n^{\alpha}}\left|\left\{k \leq n:\left|\Delta^{m} x_{k}-0\right| \geq \varepsilon\right\}\right| \geq \delta\right\} \\
& \subset\left\{n \in \mathbb{N}: \frac{[\sqrt{n}]}{n^{\alpha}} \geq \delta\right\} .
\end{aligned}
$$

Since the set on the right-hand side is a finite set and so belongs to $I$, it follows that $x_{k} \rightarrow 0\left(S^{\alpha}\left(\Delta^{m}, I\right)\right)$ for $\alpha \epsilon$ $(1 / 2,1]$. On the other hand, for $\alpha \in(0,1 / 2]$ we have

$$
\frac{\sqrt{n}-1}{n^{\alpha}} \leq \frac{1}{n^{\alpha}} \sum_{k=1}^{n}\left|\Delta^{m} x_{k}\right|^{p}=\frac{1}{n^{\alpha}} \sum_{k=1}^{n}\left|\Delta^{m} x_{k}-0\right|^{p} .
$$

Then

$$
\begin{aligned}
\left\{n_{0}, n_{0}+1, n_{0}+2, \ldots\right\} & =\left\{n \in \mathbb{N}: \frac{\sqrt{n}-1}{n^{\alpha}} \geq 1\right\} \\
& \subset\left\{n \in \mathbb{N}: \frac{1}{n^{\alpha}} \sum_{k=1}^{n}\left|\Delta^{m} x_{k}-0\right| \geq 1\right\},
\end{aligned}
$$

for some $n_{0} \in \mathbb{N}$ which belongs to $F(I)$, since $I$ is admissible. So $x_{k} \nrightarrow w^{\alpha}\left(\Delta_{p}^{m}, I\right)$.

The converse of Theorem 8 does not hold, in general. To show this, we must find a sequence that is $\Delta^{m}$-bounded and $S^{\alpha}\left(\Delta^{m}, I\right)$-convergent, but need not to be $w^{\alpha}\left(\Delta_{p}^{m}, I\right)$ summable. For this, consider a sequence $x=\left(x_{k}\right)$ defined by (10). It can be shown that $x \in \ell_{\infty}\left(\Delta^{m}\right)$ and $x \in S^{\alpha}\left(\Delta^{m}, I\right)$ for $\alpha \in(1 / 3,1]$ and $x \notin w^{\alpha}\left(\Delta_{p}^{m}, I\right)$ for $\alpha \in(0,1 / 2)$. Therefore, $x \in S^{\alpha}\left(\Delta^{m}, I\right) \backslash w^{\alpha}\left(\Delta_{p}^{m}, I\right)$ for $\alpha \in(1 / 3,1 / 2)$.

The following result is a consequence of Theorem 8 .

Corollary 9. If a sequence is $w^{\alpha}\left(\Delta_{p}^{m}, I\right)$-convergent to $L$, then it is $S^{\alpha}\left(\Delta^{m}, I\right)$-convergent to $L$.

Theorem 10. Let $0<\alpha \leq \beta \leq 1$, and let $p$ be a positive real number; then $w^{\alpha}\left(\Delta_{p}^{m}, I\right) \subset w^{\beta}\left(\Delta_{p}^{m}, I\right)$ and the inclusion is strict.

Proof. The inclusion part of proof is trivial. Taking $p=1$, we show the strictness of the inclusion $w^{\alpha}\left(\Delta_{p}^{m}, I\right) \subset w^{\beta}\left(\Delta_{p}^{m}, I\right)$ for a special case. Define the sequence $x=\left(x_{k}\right)$ such that

$$
\Delta^{m} x_{k}=\left\{\begin{array}{ll}
1, & \text { if } k=m^{2}, \\
0, & \text { if } k \neq m^{2},
\end{array} \quad m=1,2, \ldots .\right.
$$

It can easily be shown that

$$
\begin{array}{r}
\frac{1}{n^{\beta}} \sum_{k=1}^{n}\left|\Delta^{m} x_{k}-0\right| \leq \frac{\sqrt{n}}{n^{\beta}}=\frac{1}{n^{\beta-1 / 2}} \longrightarrow 0, \\
(n \longrightarrow \infty) \text { for } \beta \in\left(\frac{1}{2}, 1\right),
\end{array}
$$

but

$$
\begin{aligned}
& \frac{1}{n^{\alpha}} \sum_{k=1}^{n}\left|\Delta^{m} x_{k}-0\right|=\frac{1}{n^{\alpha}} \sum_{k=1}^{n}\left|\Delta^{m} x_{k}-0\right| \\
& \geq \frac{\sqrt{n}-1}{n^{\alpha}} \longrightarrow \infty, \\
&(n \longrightarrow \infty) \text { for } \alpha \in\left(0, \frac{1}{2}\right) .
\end{aligned}
$$

So $x \in w^{\beta}\left(\Delta_{p}^{m}, I\right)$ for $1 / 2<\beta<1$ but $x \notin w^{\alpha}\left(\Delta_{p}^{m}, I\right)$ for $0<\alpha<1 / 2$.

The following result is a consequence of Theorem 10 .

Corollary 11. Let $0<\alpha \leq \beta \leq 1$ be a positive real number. Then

(i) if $\alpha=\beta$, then $w^{\alpha}\left(\Delta_{p}^{m}, I\right)=w^{\beta}\left(\Delta_{p}^{m}, I\right)$,

(ii) $w^{\alpha}\left(\Delta_{p}^{m}, I\right) \subset w\left(\Delta_{p}^{m}, I\right)$ for each $\alpha \in(0,1]$.

Theorem 12. Let $\alpha$ and $\beta$ be fixed real numbers such that $0<$ $\alpha \leq \beta \leq 1$; then $S^{\alpha}\left(\Delta^{m}, I\right) \subset S^{\beta}\left(\Delta^{m}, I\right)$, and the inclusion is strict.

Proof. Let $x \in S^{\alpha}\left(\Delta^{m}, I\right)$. Then given $\alpha$ and $\beta$ such that $0<$ $\alpha \leq \beta \leq 1$, we may write

$$
\begin{aligned}
& \frac{1}{n^{\beta}}\left|\left\{k \leq n:\left|\Delta^{m} x_{k}-L\right| \geq \varepsilon\right\}\right| \\
& \quad \leq \frac{1}{n^{\alpha}}\left|\left\{k \leq n:\left|\Delta^{m} x_{k}-L\right| \geq \varepsilon\right\}\right|, \\
& \left\{n \in \mathbb{N}: \frac{1}{n^{\beta}}\left|\left\{k \leq n:\left|\Delta^{m} x_{k}-L\right| \geq \varepsilon\right\}\right| \geq \delta\right\} \\
& \quad \subseteq\left\{n \in \mathbb{N}: \frac{1}{n^{\alpha}}\left|\left\{k \leq n:\left|\Delta^{m} x_{k}-L\right| \geq \varepsilon\right\}\right| \geq \delta\right\} \in I
\end{aligned}
$$

and this gives that $S^{\alpha}\left(\Delta^{m}, I\right) \subset S^{\beta}\left(\Delta^{m}, I\right)$.

We show the strictness of the inclusion $S^{\alpha}\left(\Delta^{m}, I\right) \quad \subset$ $S^{\beta}\left(\Delta^{m}, I\right)$ for a special case. Define the sequence $x=\left(x_{k}\right)$ such that

$$
\Delta^{m} x_{k}=\left\{\begin{array}{ll}
k, & \text { if } k=m^{2}, \\
0, & \text { if } k \neq m^{2},
\end{array} \quad m=1,2, \ldots\right.
$$

Then $x \in S^{\beta}\left(\Delta^{m}, I\right)$ for $1 / 2<\beta \leq 1$, but $x \notin S^{\alpha}\left(\Delta^{m}, I\right)$ for $0<\alpha \leq 1 / 2$.

The following result is a consequence of Theorem 10 .

Corollary 13. Let $0<\alpha \leq 1$ be a real number; then $S^{\alpha}\left(\Delta^{m}, I\right) \subset S\left(\Delta^{m}, I\right)$.

\section{Conflict of Interests}

The authors declare that there is no conflict of interests regarding the publication of this paper. 


\section{Acknowledgment}

The authors gratefully acknowledge the financial support from King Abdulaziz University, Jeddah, Saudi Arabia.

\section{References}

[1] A. Zygmund, Trigonometric Series, Cambridge University Press, Cambridge, UK, 1979.

[2] H. Steinhaus, "Sur la convergence ordinaire et la convergence asymptotique," Colloquium Mathematicum, vol. 2, pp. 73-74, 1951.

[3] H. Fast, "Sur la convergence statistique," Colloquium Mathematicum, vol. 2, pp. 241-244, 1951.

[4] I. J. Schoenberg, "The integrability of certain functions and related summability methods," The American Mathematical Monthly, vol. 66, pp. 361-375, 1959.

[5] J. S. Connor, "The Statistical and strong $p$-Cesàro convergence of sequences," Analysis, vol. 8, pp. 47-63, 1988.

[6] M. Çınar, M. Karakaş, and M. Et, "On pointwise and uniform statistical convergence of order for sequence of functions," Fixed Point Theory and Applications, vol. 2013, article 33, 2013.

[7] M. Et, M. C. Çınar, and M. Karakaş, "On $\lambda$-statistical convergence of order of sequences of function," Journal of Inequalities and Applications, vol. 2013, article 204, 2013.

[8] J. A. Fridy, "On statistical convergence," Analysis, vol. 5, pp. 301313, 1985.

[9] M. Güngör, M. Et, and Y. Altin, "Strongly $\left(\mathrm{V}_{\sigma}, \lambda, q\right)$-summable sequences defined by Orlicz functions," Applied Mathematics and Computation, vol. 157, no. 2, pp. 561-571, 2004.

[10] M. Güngor and M. Et, " $\Delta^{r}$-strongly almost summable sequences defined by Orlicz functions," Indian Journal of Pure and Applied Mathematics, vol. 34, no. 8, pp. 1141-1151, 2003.

[11] M. Işik, "Strongly almost $(\omega, \lambda, q)$-summable sequences," Mathematica Slovaca, vol. 61, no. 5, pp. 779-788, 2011.

[12] C. Belen and S. A. Mohiuddine, "Generalized weighted statistical convergence and application," Applied Mathematics and Computation, vol. 219, pp. 9821-9826, 2013.

[13] S. A. Mohiuddine, A. Alotaibi, and M. Mursaleen, "Statistical convergence of double sequences in locally solid Riesz spaces," Abstract and Applied Analysis, vol. 2012, Article ID 719729, 9 pages, 2012.

[14] O. H. H. Edely, S. A. Mohiuddine, and A. K. Noman, "Korovkin type approximation theorems obtained through generalized statistical convergence," Applied Mathematics Letters, vol. 23, no. 11, pp. 1382-1387, 2010.

[15] M. Mursaleen, “ $\lambda$-statistical convergence," Mathematica Slovaca, vol. 50, no. 1, pp. 111-115, 2000.

[16] T. Şalàt, "On statistically convergent sequences of real numbers," Mathematica Slovaca, vol. 30, pp. 139-150, 1980.

[17] P. Kostyrko, T. Şalàt, and W. Wilczyński, "I-convergence," Real Analysis Exchange, vol. 26, pp. 669-686, 2000/2001.

[18] F. Nuray and W. H. Ruckle, "Generalized statistical convergence and convergence free spaces," Journal of Mathematical Analysis and Applications, vol. 245, no. 2, pp. 513-527, 2000.

[19] P. Das, P. Kostyrko, W. Wilczyński, and P. Malik, "I and $I^{*}$ convergence of double sequences," Mathematica Slovaca, vol. 58, no. 5, pp. 605-620, 2008.

[20] P. Das, E. Savas, and S. K. Ghosal, "On generalizations of certain summability methods using ideals," Applied Mathematics Letters, vol. 24, no. 9, pp. 1509-1514, 2011.
[21] E. Savas and P. Das, "A generalized statistical convergence via ideals," Applied Mathematics Letters, vol. 24, no. 6, pp. 826-830, 2011.

[22] P. Kostyrko, M. Mačaj, M. Sleziak, and T. Şalàt, "I-convergence and extremal I-limit points," Mathematica Slovaca, vol. 55, no. 4, pp. 443-464, 2005.

[23] B. Hazarika and S. A. Mohiuddine, "Ideal convergence of random variables," Journal of Function Spaces and Applications, vol. 2013, Article ID 148249, 7 pages, 2013.

[24] S. A. Mohiuddine, A. Alotaibi, and S. M. Alsulami, "Ideal convergence of double sequences in random 2-normed spaces," Advances in Difference Equations, vol. 2012, article 149, 2012.

[25] M. Mursaleen and S. A. Mohiuddine, "On ideal convergence in probabilistic normed spaces," Mathematica Slovaca, vol. 62, no. 1, pp. 49-62, 2012.

[26] T. Şalàt, B. C. Tripathy, and M. Ziman, "On I-convergence field," Italian Journal of Pure and Applied Mathematics, vol. 17, pp. 4554, 2005.

[27] T. Şalàt, B. C. Tripathy, and M. Ziman, "On some properties of $I$ convergence," Tatra Mountains Mathematical Publications, vol. 28, part II, pp. 279-286, 2004.

[28] B. C. Tripathy and B. Hazarika, "Paranorm I-convergent sequence spaces," Mathematica Slovaca, vol. 59, no. 4, pp. 485494, 2009.

[29] B. C. Tripathy and B. Hazarika, "Some I-convergent sequence spaces defined by Orlicz functions," Acta Mathematicae Applicatae Sinica, vol. 27, no. 1, pp. 149-154, 2011.

[30] A. D. Gadjiev and C. Orhan, "Some approximation theorems via statistical convergence," Rocky Mountain Journal of Mathematics, vol. 32, no. 1, pp. 129-138, 2002.

[31] R. Çolak, Statistical Convergence of Order, Modern Methods in Analysis and Its Applications, Anamaya, New Delhi, India, 2010.

[32] H. Kizmaz, "On certain sequence spaces," Canadian Mathematical Bulletin, vol. 24, no. 2, pp. 169-176, 1981.

[33] M. Et, "Strongly almost summable difference sequences of order $\mathrm{m}$ defined by a modulus," Studia Scientiarum Mathematicarum Hungarica, vol. 40, no. 4, pp. 463-476, 2003.

[34] M. Et, Y. Altin, B. Choudhary, and B. C. Tripathy, "On some classes of sequences defined by sequences of orlicz functions," Mathematical Inequalities and Applications, vol. 9, no. 2, pp. 335342, 2006.

[35] M. Et, "Generalized Cesàro difference sequence spaces of nonabsolute type involving lacunary sequences," Applied Mathematics and Computation, vol. 219, no. 17, pp. 9372-9376, 2013.

[36] B. Altay and F. Başar, "On the fine spectrum of the difference operator $\Delta$ on $c_{0}$ and $c$," Information Sciences, vol. 168, no. 1-4, pp. 217-224, 2004.

[37] Y. Altin, M. Et, and M. Basarir, "On some generalized difference sequences of fuzzy numbers," Kuwait Journal of Science and Engineering, vol. 34, no. 1A, pp. 1-14, 2007.

[38] R. Çolak, H. Altinok, and M. Et, "Generalized difference sequences of fuzzy numbers," Chaos, Solitons and Fractals, vol. 40, no. 3, pp. 1106-1117, 2009.

[39] B. C. Tripathy, Y. Altin, and M. Et, "Generalized difference sequence spaces on seminormed space defined by Orlicz functions," Mathematica Slovaca, vol. 58, no. 3, pp. 315-324, 2008.

[40] H. Gumus, I-Convergence and asymptotic I-equivalence of difference sequences [Ph.D. thesis], Afyon Kocatepe University, 2011. 


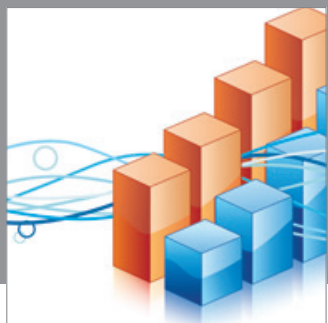

Advances in

Operations Research

mansans

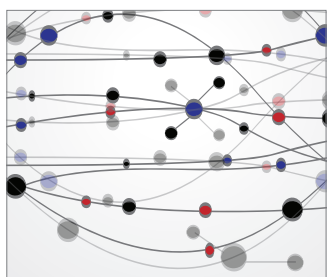

The Scientific World Journal
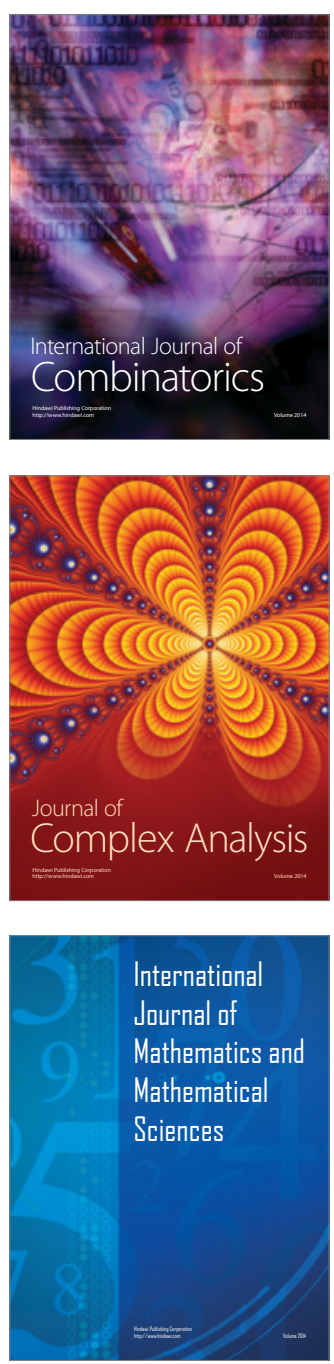
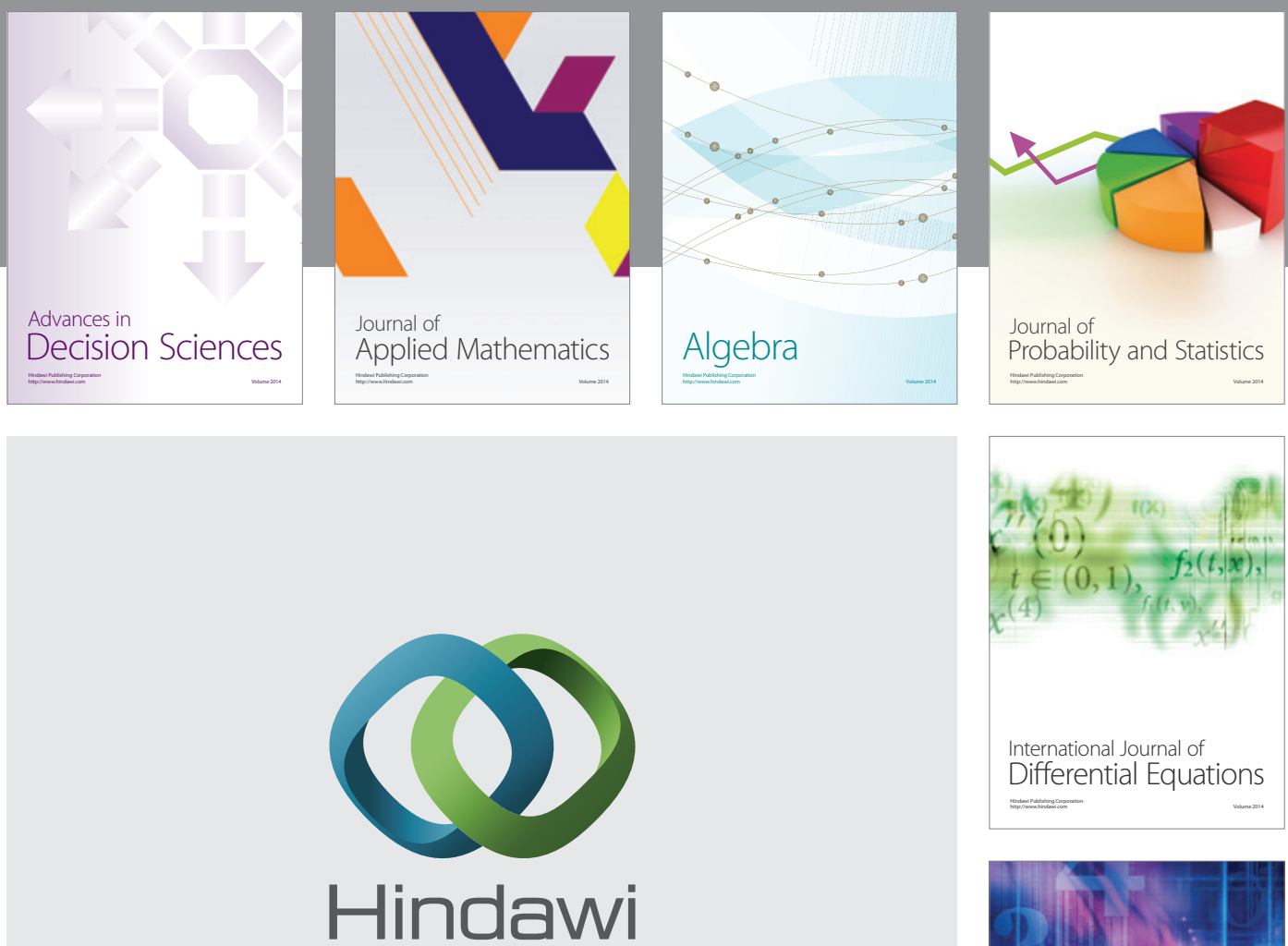

Submit your manuscripts at http://www.hindawi.com
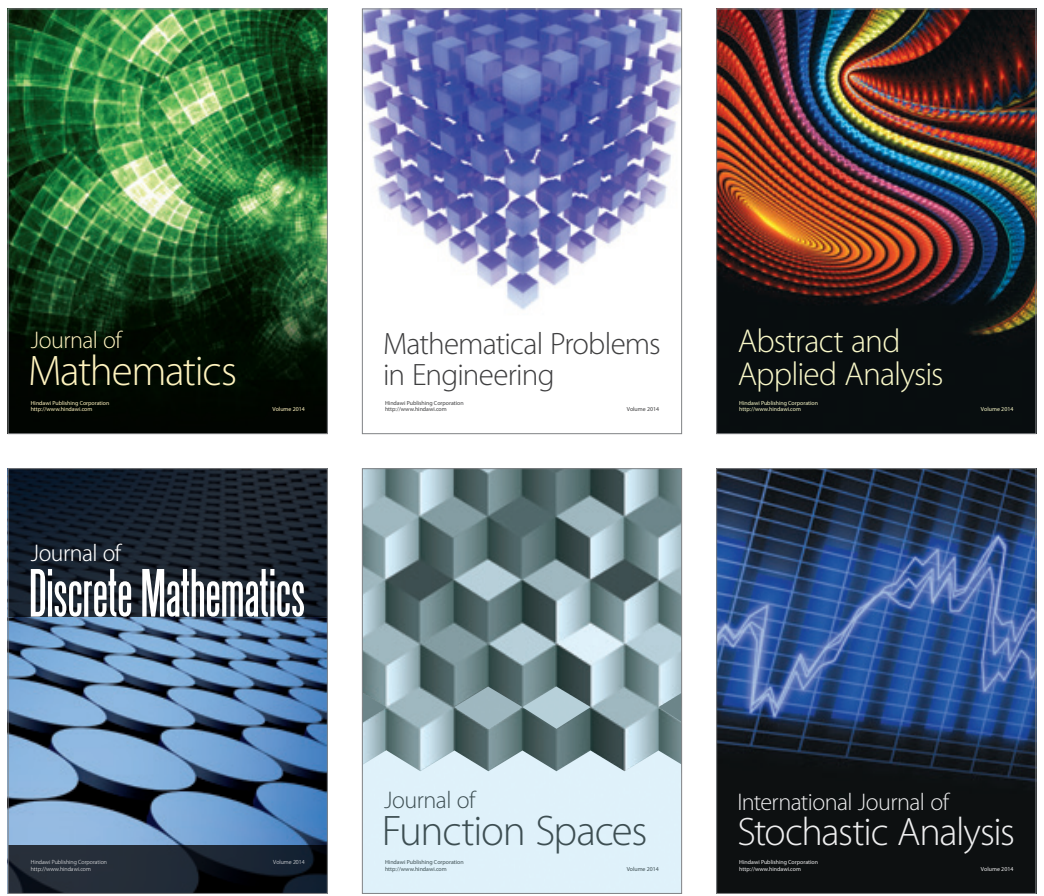

Journal of

Function Spaces

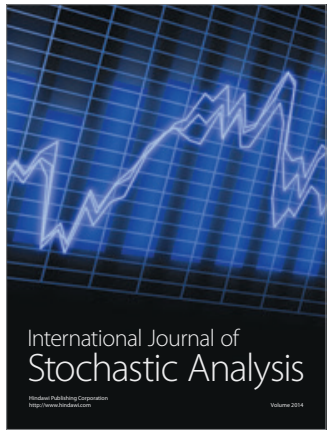

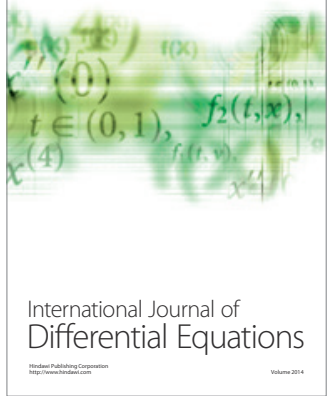
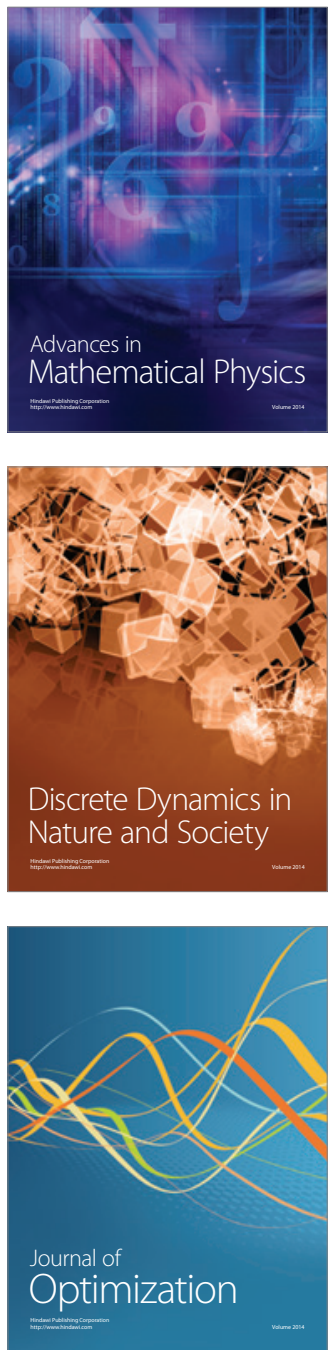